\title{
Early trabeculectomy versus conventional management in primary open angle glaucoma
}

\author{
J L JAY AND S B MURRAY \\ From the Tennent Institute of Ophthalmology, University of Glasgow, Western Infirmary, Glasgow G11 6NT
}

SUMmARY The results of a randomised, prospective, multicentre trial of the management of primary open angle glaucoma are presented at up to five years' follow up. Previously undiagnosed cases were selected with intraocular pressure of $26 \mathrm{mmHg}$ or more on two occasions together with field loss characteristic of glaucoma. Analysis was performed on one eye selected at random from each of 99 patients. Conventional medical treatment followed in unsuccessful cases by trabeculectomy (group A) was compared with trabeculectomy at diagnosis followed when necessary by supplementary medical therapy (group B). The life expectancy of these glaucoma patients was found to be similar to that for the local population matched for age and sex. In group A after four years trabeculectomy had been performed in $53 \%$ of eyes because medical management had failed to control the disease. The rate of operation was lower in those patients with intraocular pressure less than $31 \mathrm{mmHg}$ and mild relative field loss (17\% at three years) than in those with intraocular pressure greater than $30 \mathrm{mmHg}$ and dense scotomas $(75 \%$ at three years). Early surgery provided much more stable control with fewer changes in treatment than in group $\mathrm{A}$. The group mean intraocular pressure after trabeculectomy was $15.0 \mathrm{mmHg}$ irrespective of the time of operation, and this was significantly lower than the intraocular pressure in those cases thought to be controlled on medical therapy alone at the end of the first year $(20.8 \mathrm{mmHg})$. Early operation provided significantly better protection of visual field, and the extra loss of visual field with delayed operation occurred in the preoperative period. Changes in visual fields were not related to the use of miotics. There was no significant difference in the final visual acuity in the two groups, but six cases in group A lost central fixation because of progressive loss of visual field, and there were no such cases in group B. Cataract occurred in approximately $10 \%$ of cases in both groups, but in group A this happened with only half the number of operations and at a shorter postoperative follow-up than in group B. It appears that in cases of primary open angle glaucoma of this severity the risk of delaying operation are significantly greater than those of performing trabeculectomy as the primary treatment.

This is the second report on the progress of a prospective, randomised, multicentre trial of the management of primary open angle glaucoma. Preliminary results were reported in $1983,{ }^{1}$ and data are now available at up to five years of follow-up. The aim is to test whether with the increased safety of trabeculectomy over earlier drainage operations it is still justifiable to persist with the conventional practice of using medical therapy as the first line of treatment. Other workers are studying the same question, and it seems agreed that trabeculectomy

Correspondence to Dr J L Jay, Tennent Institute of Ophthalmology, Western Infirmary, Glasgow G11 6NT. provides a lower intraocular pressure with less diurnal variation than medical therapy or argon laser trabeculoplasty. ${ }^{2}$ In addition, successful surgery avoids the uncertainties of medical therapy associated with the limited duration of each drug application and the possible failure of the patient to use treatment as directed. ${ }^{3-5}$ Smith ${ }^{67}$ has compared the long-term results of medical versus surgical therapy at up to 18 years. His results indicate that drainage surgery is superior to medical therapy in lowering intraocular pressure and that early randomised operation was not detrimental to visual acuity in comparison with cases initially allocated to medical 
therapy. Changes in visual field were less conclusive but did suggest that early operation might have a beneficial effect. It should be noted that this study was carried out on a group with relatively low mean untreated intraocular pressure at diagnosis (25 $\mathrm{mmHg}$ ) and that there have been more recent major advances in both medical and surgical treatment.

We have therefore compared conventional management, where trabeculectomy is carried out only after demonstrable failure of medical therapy, with primary trabeculectomy, where operation is performed as soon as possible after diagnosis. The results of trabeculectomy in our hands confirm that it is a safe and effective procedure. ${ }^{89}$

\section{Patients and methods}

A collaborative trial was set up to study the patients of nine consultant ophthalmologists based in five Glasgow hospitals. All were consecutive and previously undiagnosed cases of primary open angle glaucoma, including those with pseudoexfoliation. Patients were accepted if the untreated intraocular pressure was $26 \mathrm{mmHg}$ (Goldmann) or more on two occasions and if field defects characteristic of glaucoma were present. They were allocated to one of two treatment groups by means of a table of random numbers.

Group A was treated conventionally with up to a maximum of three different topical or systemic drugs. Where maximum tolerated medical treatment was insufficient to control the intraocular pressure or prevent loss of visual field, trabeculectomy as described by Watson ${ }^{10}$ was performed, usually with local anaesthesia.

Group B had trabeculectomy as soon as possible within four weeks of diagnosis, but preliminary medical therapy was used where necessary to reduce the intraocular pressure to a safe level prior to surgery. In both groups postoperative medical therapy was introduced when indicated according to the usual clinical criteria.

Visual acuity (Snellen), visual field (Tübingen), and intraocular pressure (Goldmann) measurements and optic disc photographs were taken at the Tennent Institute on entry to the trial and at yearly intervals thereafter.

Visual field tests were carried out as part of the standard glaucoma clinic assessment by ophthalmic opticians specially trained as perimetrists. Patients were not separately identified as belonging to a clinical trial. Examinations at appropriate intervening periods were carried out by the referring ophthalmologists, who remained responsible for all decisions in the management of their own patients after the initial random allocation into groups $\mathrm{A}$ and $\mathrm{B}$. In cases of group A which eventually required operation the indications for operation were recorded. Surgery was performed in the referring hospital by whichever surgeon was deemed appropriate in the normal practice of that hospital. No attempt was made to limit the operation to selected surgeons. The clinical findings including copies of field charts were sent to the referring ophthalmologist after each annual assessment.

No statement of opinion or advice about past or future management was made. The referring surgeons were not given any fixed criteria for adequate pressure control or significant change in visual field but, as stated above for group A, no patient was to be maintained on more than three separate topical or systemic drugs. In principle the surgeons agreed that a treated intraocular pressure of approximately 20 $22 \mathrm{mmHg}$ did not of itself indicate adequate pressure control except where it represented a marked reduction from the pretreatment level in an eye with mild field loss or cupping. They made their own clinical decisions about the significance of visual field changes based on the field tests carried out in their own hospital supplemented by the annual results supplied by the trial investigator.

A simple punched card sorting system was used to store and analyse the following details of patients at entry to the trial: sex, age, general health, initial symptoms or reason for diagnosis, visual acuity, visual fields, maximum intraocular pressure before treatment, and appearance of the optic discs. Each year further information was entered about changes

Table 1 Classification of visual field changes

\begin{tabular}{ll}
\hline Stage & Visual field loss \\
\hline 1 & Early relative defects (to $1 \cdot 0 / 10$ asb Tübingen; equivalent to \\
& I-2e Goldmann) in arcuate area or nasal step \\
2 & Absolute defects (to $1 \cdot 0 / 00$ asb Tübingen; equivalent to I-4e \\
& Goldmann) outside $10^{\circ}$ of fixation in all quadrants \\
3 & As stage 2 but encroaching between $5^{\circ}$ and $10^{\circ}$ from fixation \\
& in 1 to 4 quadrants \\
4 & As stage 2 but within $5^{\circ}$ of fixation in 1 to 3 quadrants \\
5 & As stage 2 but within $5^{\circ}$ of fixation in all quadrants \\
\hline
\end{tabular}

Table 2 Classification of optic disc changes at diagnosis and the percentage distribution within each group

\begin{tabular}{llrr}
\hline Grade & Optic disc appearance & \multicolumn{2}{c}{ Group } \\
\cline { 3 - 4 } & & \multicolumn{1}{c}{$A$} & \multicolumn{1}{c}{$B$} \\
\hline 1 & C/D $\leqslant 0.6$ & $25 \%$ & $30 \%$ \\
2 & Suspicious shape of optic cup but C/D $\leqslant 0.6$ & $6 \%$ & $4 \%$ \\
3 & Pathological, $0 \cdot 6<$ C/D $<0.9$ & $29 \%$ & $28 \%$ \\
4 & End Stage, C/D $>0.9$ & $40 \%$ & $37 \%$ \\
\hline
\end{tabular}

$\mathrm{C} / \mathrm{D}=$ Vertical cup to disc ratio. 

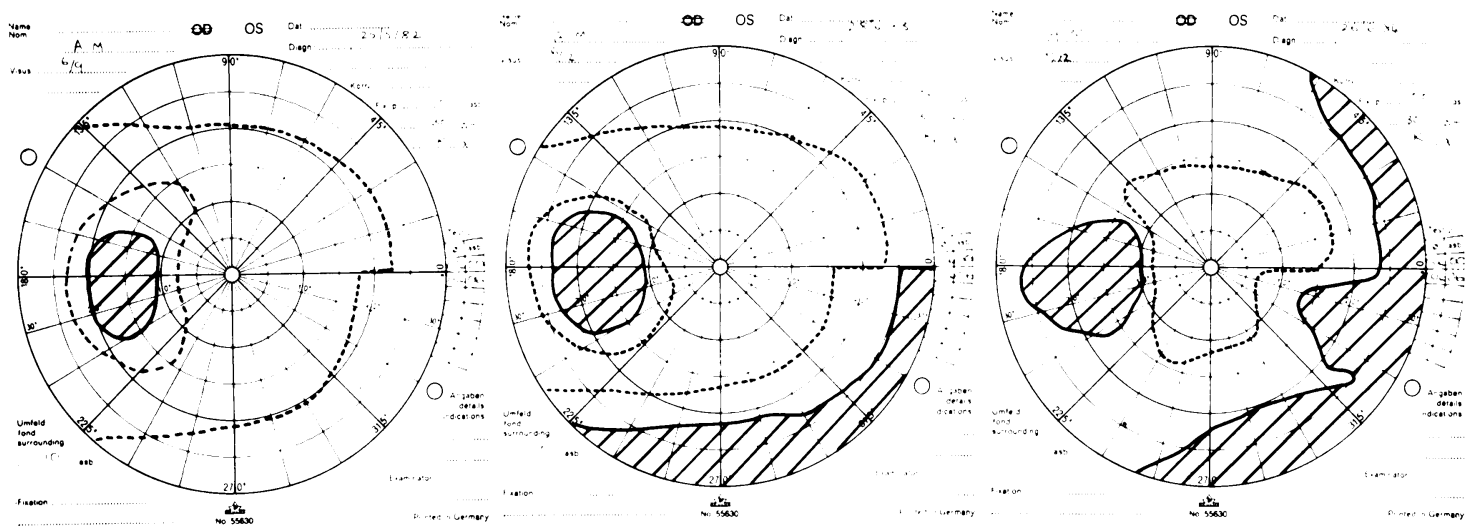

Fig. 1 Annual visual field tests illustrating (left) stage 1 field changes in 1982, (centre) progressing to stage 2 by 1983, (right) further significant change by 1984 but remaining in stage 2 of the classification.
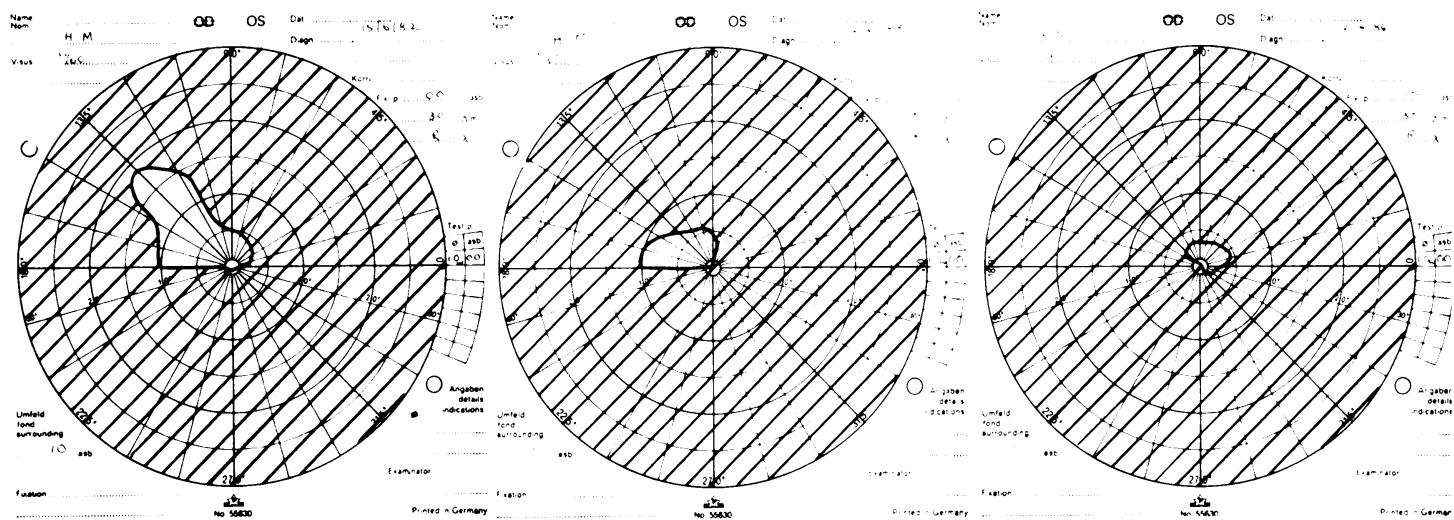

Fig. 2 A more severe example commencing (left) in stage 4 of the visual field classification in 1982, (centre) showing significant progression within stage 4 by 1983, and (right) further progression into stage 5 by 1984.

in visual acuity, visual fields, intraocular pressure, disc appearances, and management. To simplify the records an arbitrary classification of the visual field changes was devised as shown in Table 1 and the optic disc changes were graded as shown in Table 2. Table 2 also shows the distribution of optic disc changes in each group. The change in visual field at yearly intervals was assessed by an experienced observer familiar with the expected variation in the test system. Any significant alteration in density or area of field loss was noted, and separate data were recorded for cases with more severe field change causing deterioration by one stage or more.

Figs. 1 and 2 illustrate the classification of field loss and the amount of change which was considered significant. Examples of change within a stage of the classification as well as across stage boundaries are given. Where both eyes of a patient were included in the trial, one was selected at random for the analysis of results.
To discover whether the extra loss of visual field of group A over group B had occurred before or after the delayed trabeculectomy, the 26 group A eyes which had required operation were paired with eyes selected from group $\mathrm{B}$ to have a comparable period of postoperative follow-up. This selection was necessary because the whole group could not be used, since the available postoperative follow-up period for group A was shorter than for group B. The pairs were matched in order of priority for: stage of visual field at diagnosis (100\% match), duration of postoperative follow-up $(100 \%$ match $)$, intraocular pressure at diagnosis $(92 \%$ match with $\pm 20 \%$ of pressure at diagnosis and $50 \%$ match with $\pm 10 \%$ of pressure at diagnosis), age ( $46 \%$ match within 10 years), and sex (80\% match).

To take account of the improvement in visual field which may occur with therapy a simple digital scoring system was used. Increase or decrease of field within a stage was awarded + or $-0 \cdot 5$, and for each stage 
boundary crossed + or $-1 \cdot 0$. Statistical analysis was performed with the Minitab package of the University of Glasgow computer using $t, \chi^{2}$, and nonparametric tests as appropriate. The main features of each group were compared at diagnosis and at each year of follow-up.

A life table was constructed for the patients under study and compared with the life expectancy of the local population.

\section{Results}

Patients were recruited at a rate of approximately 25 per year. Ninety-nine completed at least one year in the trial, 53 in group A and 46 in group B. Another four patients initially allocated to group $B$ refused operation and were excluded from the analysis. The mean age at diagnosis was 67.4 years for group $A$ and 64.3 years for group $B$, and the group mean intraocular pressure at diagnosis was $35.9 \mathrm{mmHg}$ for group $\mathrm{A}$ and $36.1 \mathrm{mmHg}$ for group $\mathrm{B}$. There was no significant difference between the groups at the start of the trial for sex $(0 \cdot 05<\mathrm{p}<0 \cdot 1)$, age $(0 \cdot 1<\mathrm{p}<0 \cdot 2)$, right or left eyes $(p>0.5)$, visual acuity $(0.05<$ $p<0 \cdot 1)$, visual fields $(p>0 \cdot 5)$, optic discs $(p>0.05)$, intraocular pressure $(\mathrm{p}>0.5)$, or incidence of systemic disease $(p>0.5)$. The Mann-Whitney test was used for age and intraocular pressure, $\chi^{2}$ for other

Table 3 Patients available for study at end of each year, indicating numbers dead or lost to follow-up

\begin{tabular}{|c|c|c|c|c|c|c|c|}
\hline \multirow{3}{*}{$\begin{array}{l}\text { At end } \\
\text { of year }\end{array}$} & \multirow{2}{*}{\multicolumn{2}{|c|}{$\begin{array}{l}\text { No. available } \\
\text { for study }\end{array}$}} & \multicolumn{3}{|c|}{ No. dead } & \multirow[t]{3}{*}{$\%$ Dead } & \multirow{3}{*}{$\begin{array}{l}\text { Lost to } \\
\text { follow-up }\end{array}$} \\
\hline & & & $A$ & $B$ & $A+B$ & & \\
\hline & $A$ & $B$ & & & & & \\
\hline 1 & 53 & 46 & 1 & 3 & 4 & 4 & 0 \\
\hline 2 & 36 & 39 & 4 & 3 & 7 & 9 & 1 \\
\hline 3 & 25 & 24 & 4 & 3 & 7 & 12 & 1 \\
\hline 4 & 15 & 15 & 2 & 1 & 3 & 9 & 0 \\
\hline 5 & 5 & 3 & 1 & 1 & 2 & 20 & 0 \\
\hline
\end{tabular}

Table 4 Percentage of eyes in group A having trabeculectomy because of failure of medical control. The figures indicate cumulative data from diagnosis to the end of the year stated. Very few cases with $I O P>30 \mathrm{mmHg}$ and with field loss more advanced than stage 1 at diagnosis have avoided operation at the end of the second and third years

\begin{tabular}{|c|c|c|c|c|}
\hline \multirow{2}{*}{\multicolumn{2}{|c|}{$\begin{array}{l}\text { At end Whole } \\
\text { of year group }\end{array}$}} & \multicolumn{3}{|c|}{ Stratified by severity of disease at diagnosis } \\
\hline & & \multicolumn{3}{|c|}{$\begin{array}{l}I O P<31 \mathrm{mmHgIOP}>30 \mathrm{mmHg} \quad \text { IOP }>35 \mathrm{~mm} \mathrm{Hg} \\
\text { and field stage } 1 \text { and field stage } 2-5 \text { and field stage } 3-5\end{array}$} \\
\hline 1 & $32 \%$ & $8 \%$ & $58 \%$ & $63 \%$ \\
\hline 2 & $47 \%$ & $33 \%$ & $60 \%$ & $80 \%$ \\
\hline 3 & $52 \%$ & $17 \%$ & $75 \%$ & $78 \%$ \\
\hline 4 & $53 \%$ & \multicolumn{3}{|c|}{ Numbers insufficient for analysis } \\
\hline
\end{tabular}

factors. The mean time of latest follow-up was 30 months for group A and 33 months for group B.

Table 3 shows the numbers available at each year of follow-up. Those known to be dead are indicated, and one patient was lost to follow-up. Life table analysis showed that the number dying (12 males, 4 females) was not significantly different $(p>0 \cdot 2$, Poisson distribution) from that expected in the local population matched for age and sex (14.1 males, $6 \cdot 7$ females). Between group A and group B the death rate was comparable.

Table 4 shows the frequency and timing of operation in group $\mathrm{A}$ (conventional management) in those eyes where satisfactory medical control was not possible. The rate for the whole group increased from $32 \%$ at one year to $53 \%$ at four years, but medical therapy was more likely to be abandoned in the more severe cases. Thus in cases of milder disease, arbitrarily defined at diagnosis as intraocular pressure $<31 \mathrm{mmHg}$ with stage 1 field loss, those requiring operation increased from $8 \%$ at one year to $17 \%$ at three years. In cases of more severe disease, an intraocular pressure $>30 \mathrm{mmHg}$ and having absolute field defects (stage 2 or more, see Table 1), the operation rate was $58 \%$ at one year and $75 \%$ at three years. Further stratification to identify the worst cases ( $>35 \mathrm{mmHg}$; Field stage 3 to 5 ) indicated a slightly higher rate of operation, $63 \%$ at one year and $78 \%$ at three years.

The reasons given by the referring surgeon for

Table 5 Indications for abandoning medical therapy and proceeding to trabeculectomy in group $A$

\begin{tabular}{|c|c|c|c|c|c|}
\hline \multirow{3}{*}{$\begin{array}{l}\text { Time from } \\
\text { diagnosis } \\
\text { to operation } \\
\text { (months) }\end{array}$} & \multirow[t]{3}{*}{$n$} & \multicolumn{4}{|c|}{ Indications for operation } \\
\hline & & Uncontrolled & Uncontrolled & Controlled & Other \\
\hline & & $I O P$ & $\begin{array}{l}\text { IOP and } \\
\text { increasing } \\
\text { field loss }\end{array}$ & $\begin{array}{l}\text { IOP but } \\
\text { increasing } \\
\text { field loss }\end{array}$ & \\
\hline $0-3$ & 6 & 6 & 0 & 0 & 0 \\
\hline $4-12$ & 11 & 6 & 2 & 3 & 0 \\
\hline $13-24$ & 6 & 0 & 3* & 2 & $1 \dagger$ \\
\hline $25-33$ & 3 & $2^{*}$ & 1 & 0 & 0 \\
\hline
\end{tabular}

*One of these patients identified with poor compliance.

†Intolerant of all medical therapy.

Table 6 Eyes requiring changes of therapy during each year

\begin{tabular}{|c|c|c|c|c|c|c|}
\hline \multirow[t]{2}{*}{ Year } & \multicolumn{3}{|c|}{ Group $A$} & \multicolumn{3}{|c|}{ Group B } \\
\hline & $n$ & $\begin{array}{l}\text { Extra } \\
\text { medical } \\
\text { therapy }\end{array}$ & Operation & $n$ & $\begin{array}{l}\text { Extra } \\
\text { medical } \\
\text { therapy }\end{array}$ & Operation \\
\hline 1 & 53 & 16 & 17 & 46 & 7 & (46) \\
\hline 2 & 35 & 5 & 6 & 39 & 1 & 0 \\
\hline 3 & 25 & 5 & 3 & 24 & 2 & 0 \\
\hline 4 & 14 & 4 & 0 & 15 & 0 & 1 \\
\hline
\end{tabular}




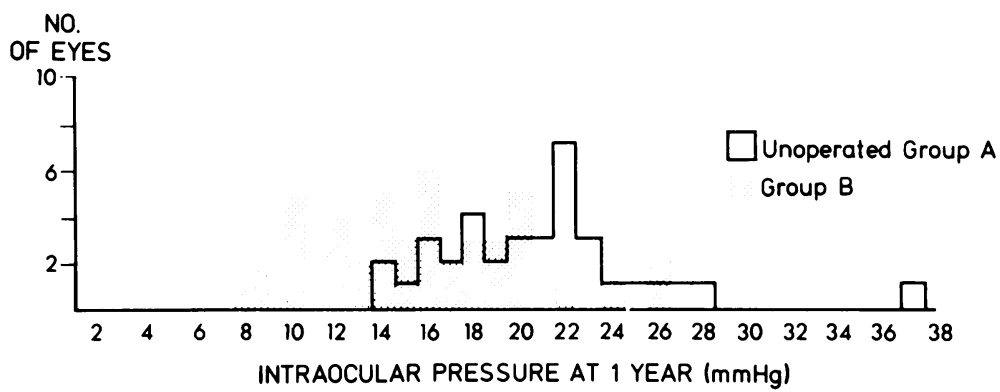

Fig. 3 Histogram comparing the intraocular pressure at one year achieved by medical therapy in group A eyes which were thought to be controlled without surgery (mean $=20.8 \mathrm{mmHg}$ ) and the pressure in group $B$ who had trabeculectomy at diagnosis (mean $=15.0 \mathrm{mmHg}$ ). None of the patients in group $B$ were using supplementary medical treatment. proceeding to operation in these group A eyes are set out in Table 5. Unacceptably high intraocular pressure was the only indication for operation within three months of diagnosis; thereafter progressive loss of visual field with or without recognised high intraocular pressure became more frequent. The proportion of group A cases proceeding to trabeculectomy in the first year after entry was examined for each year of the trial to determine if the referring surgeons were changing their indications for abandoning medical therapy. There was a slight increase in the rate of operation in group $A$ in the later years, but this was not significant $\left(p>0.5 ; \chi^{2}\right)$.

To compare the relative effectiveness of medical therapy with trabeculectomy in reducing intraocular pressure, the pressures in those eyes in group A on medical therapy which had not required operation were compared with the pressures in group B. None of Group B were having supplementary medical treatment at the time of this comparison at the end of the first year, though some did require supplementary therapy thereafter (Table 6 ). The $32 \%$ of group A where medical control had already proved impossible (Table 4) are not included. Fig. 3 displays the lower intraocular pressure achieved by trabeculectomy (mean $=15.0 \mathrm{mmHg}$ ) compared with those apparently controlled on medical therapy alone (mean $=20.8 \mathrm{mmHg}$ ). The difference is significant $(p<0 \cdot 001$, Mann-Whitney). Of the nine patients in group A with intraocular pressure $22 \mathrm{mmHg}$ at this examination three were not using eyedrops as directed and another three were judged to be unsatisfactory and had their treatment changed. The raised pressure in these six eyes identified at the one-year assessment was unexpected and much higher than previously noted by the referring surgeon (the remaining three eyes were known to have treated pressures in the region of $22 \mathrm{mmHg}$, which was considered acceptable by the referring ophthalmologist). Even if these six eyes are excluded from the group A. data to obtain a group mean intraocular pressure of those judged well enough controlled after this examination to continue with unchanged treat- ment, the mean pressure of $19.5 \mathrm{mmHg}$ is still significantly higher than all group $B$ eyes at one year ( $<<0 \cdot 001$, Mann-Whitney).

The mean intraocular pressure after trabeculectomy without supplementary medical therapy was identical whether the operation was carried out as a primary procedure (group B) or only after failure of medical therapy (group A). In both cases the mean pressure was $15.0 \mathrm{mmHg}$.

Figs. 4 and 5 display changes in visual field of at least one full stage of the classification from diagnosis to latest follow-up. The data for group $\mathrm{A}$ include those eyes which could not be controlled by medical means and which eventually required operation. Comparison of the figures confirms that group A showed more frequent and more severe loss of visual field than group B. Application of the Mann-Whitney test to take account of the numbers showing change and the degree of change in each case shows these differences are significant $(0.02<p<0.05)$. The risk of progression of field defects was not related to the severity of loss at diagnosis; those with mild field defects were just as likely to have progressive deterioration as those with advanced disease.

Several patients showed improvement in visual field with treatment, but this was more common and more marked in Group B. The changes in visual field cannot be explained by variations in miotic therapy. All initial field tests were performed before starting treatment, and in group B no eyes were on miotic therapy at the latest examination. In group A 13 eyes were on pilocarpine at the latest follow-up, but, of these, six showed field tests which were unchanged or improved and another six showed field deterioration which had occurred before the introduction or during stable dosage of pilocarpine.

Tables 7 and 8 show the percentage of eyes in each group with visual field deterioration from diagnosis to the end of each completed year. Any field change judged to be significant by an experienced observer is included for Table 7, but only the more strict criteria, loss of field severe enough to transfer from one stage of the classification to another, are considered for 


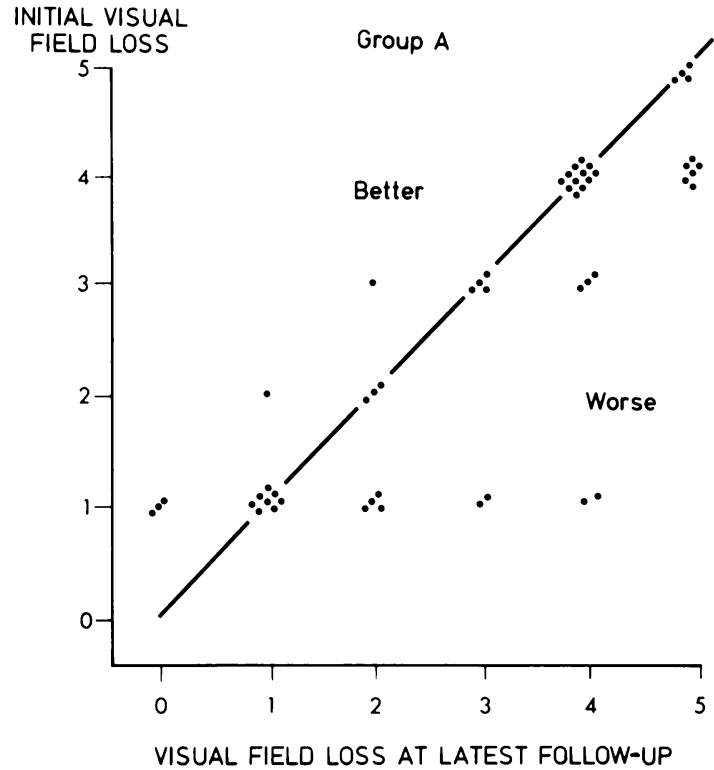

Fig. 4 Visual field change at latest follow-up (mean $=30$ months) in all group $A$ eyes.

Table 8. It therefore represents those eyes with more serious and sight threatening deterioration. By both standards of assessment approximately twice as many eyes in group $A$ lost field as in group $B$ at each year of follow-up. $p$ Values by $\chi^{2}$ test are indicated.

To determine whether the increased loss of field of group A over group B had occurred before trabeculectomy, and during the trial of medical treatment rather than after operation, the relative performance of the matched pairs was analysed by the digital scoring system. There was no significant difference between the two groups for postoperative field damage $(0.2<p<0.5$, Wilcoxon signed rank test $)$, but the preoperative field loss for group $A$ was greater than the postoperative loss $(0 \cdot 1<\mathrm{p}<0 \cdot 02$, Mann-

Table 7 Percentage of eyes in each group showing deterioration in visual fields from time of diagnosis to end of year stated

\begin{tabular}{|c|c|c|c|c|c|}
\hline \multirow{3}{*}{$\begin{array}{l}\text { At end } \\
\text { of year }\end{array}$} & \multicolumn{5}{|c|}{ Percentage losing field from time of diagnosis } \\
\hline & \multicolumn{2}{|c|}{ Group A } & \multicolumn{2}{|c|}{ Group B } & \multirow[t]{2}{*}{$\chi^{2}$} \\
\hline & $n$ & $\%$ & $n$ & $\%$ & \\
\hline 1 & 53 & 51 & 46 & 20 & $0.001<\mathrm{p}<0.01$ \\
\hline 2 & 36 & 55 & 39 & 25 & $0.01<\mathrm{p}<0.02$ \\
\hline 3 & 25 & 60 & 24 & 25 & $0.01<\mathrm{p}<0.02$ \\
\hline 4 & 15 & 53 & 15 & 33 & Not significant* \\
\hline
\end{tabular}

*Numbers too small for valid analysis.

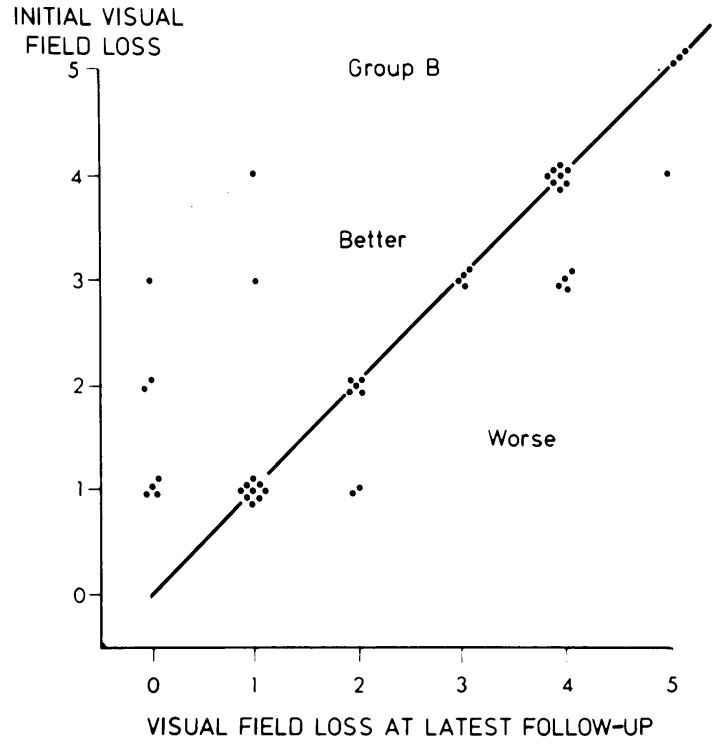

Fig. 5 Visual field change at latest follow-up in group $B$ (mean=33 months). Comparison with Fig. 2 shows the detrimental effect of delaying operation until medical therapy is seen to be unsuccessful. Group B is significantly different from group $A(0.02<p<0.05)$.

Whitney test) (Table 9). Using a change of vertical cup to disc ratio of \pm 0.1 or more, we found no significant difference in the appearance of the optic discs of each group at latest follow-up, but the trend favoured group B.

Very few eyes showed change in corrected Snellen visual acuity of more than one line (Figs. 6 and 7). The slightly greater number in group $A$ with reduced acuity of more than one line is not significant $\left(0.2<p<0.5, \chi^{2}\right)$. Nevertheless this overall assessment hides important changes in group $\mathrm{A}$, as six eyes in this group lost central fixation because of progressive field loss - four in the first year, one in the

Table 8 Percentage of eyes in each group showing deterioration in visual field by one stage or more from time of diagnosis to end of year stated

\begin{tabular}{|c|c|c|c|c|c|}
\hline \multirow[t]{3}{*}{$\begin{array}{l}\text { At end } \\
\text { of year }\end{array}$} & \multicolumn{5}{|c|}{$\begin{array}{l}\text { Percentage losing field by one stage or more from time } \\
\text { of diagnosis }\end{array}$} \\
\hline & \multicolumn{2}{|c|}{ Group A } & \multicolumn{2}{|c|}{ Group B } & \multirow[t]{2}{*}{$\chi^{2}$} \\
\hline & $n$ & $\%$ & $n$ & $\%$ & \\
\hline 1 & 53 & 26 & 46 & 9 & $0.02<\mathrm{p}<0.05$ \\
\hline 2 & 36 & 25 & 39 & 15 & Not significant \\
\hline 3 & 25 & 36 & 24 & 8 & $0.02<\mathrm{p}<0.05$ \\
\hline 4 & 15 & 40 & 15 & 20 & Not significant* \\
\hline
\end{tabular}

*Numbers too small for valid analysis. 
Table 9 Digital score for visual field change for the 26 eyes in group $A$ which eventually required operation compared with 26 matched controls from group $B$

$\left.\begin{array}{lrl}\hline \text { Group } & \text { Net score } & p \\
\hline \text { Group A. Preoperative change } & -10.0 \\
\text { Group A. Postoperative change } & -1.0 & 0.018 \text { (significant) } \\
\text { Group B. Postoperative change } & -4.5\end{array}\right\}$\begin{tabular}{ll}
0.266 (not significant) \\
\hline
\end{tabular}

second, and one in the third year. There were no comparable events in group B. Progressive lens opacity, usually nuclear sclerosis, was the only other cause of reduced visual acuity. These progressive cataracts were more likely to arise in previously normal lenses than in the $20 \%$ of cases which showed incipient cataract before glaucoma treatment. The overall $10 \%$ incidence of cataract producing reduction of more than one line in visual acuity was similar in the two groups (Table 10). Of the six cases of cataract in group A one appeared before operation. Although the incidence of cataract in group $\mathrm{A}$ was similar to that in group B, this occurred in a group with fewer operations (53\% at three years, Table 4$)$, and the average postoperative follow-up time for those who did have operation in group A (22 months) was shorter than that in group B (33 months). The numbers with cataract, however, were too small for valid statistical comparison.

\section{Discussion}

This clinical trial was designed not to test the intrinsic

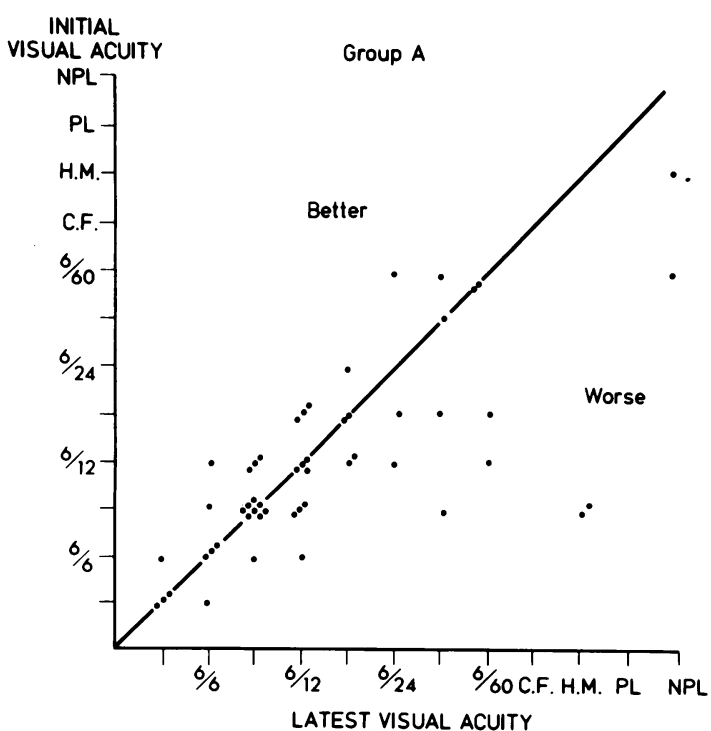

Fig. 6 Change in visual acuity from diagnosis to latest follow-up in group $A$ (mean $=30$ months). Six cases lost central fixation because of progressive visual field loss. merits of surgical or medical therapy but to discover the sequence in which they should be used. The results provide a basis for the assessment of risks and benefits of trabeculectomy as primary treatment with secondary support from medical therapy compared with the hitherto more conventional reverse sequence. The multicentre design of the study makes it more relevant as a guide to other surgeons who might otherwise remain sceptical of results from one individual, who might be considered to have greater or lesser skills in medical or surgical management. We therefore feel that our trial is a valid test of the two treatment strategies as they might be applied in the average glaucoma clinic in the United Kingdom.

Only cases with initial intraocular pressure of 26 $\mathrm{mmHg}$ or more were studied, and therefore the findings should not be extrapolated to the glaucoma population with lower pressures. For the severity of glaucoma studied it is clear, however, that the initial attempt at medical control in group A merely delays trabeculectomy in many cases. This delay has been identified by others, ${ }^{12}$ and it is a criticism which also applies to argon laser trabeculoplasty..$^{13}$ Where the initial intraocular pressure is over $30 \mathrm{mmHg}$ with dense, though not necessarily extensive, field defects, over $75 \%$ of cases treated conventionally (group A) require trabeculectomy within three years.

This delayed operation is just as effective as primary surgery in reducing intraocular pressure, and in both cases operation is more effective at doing so

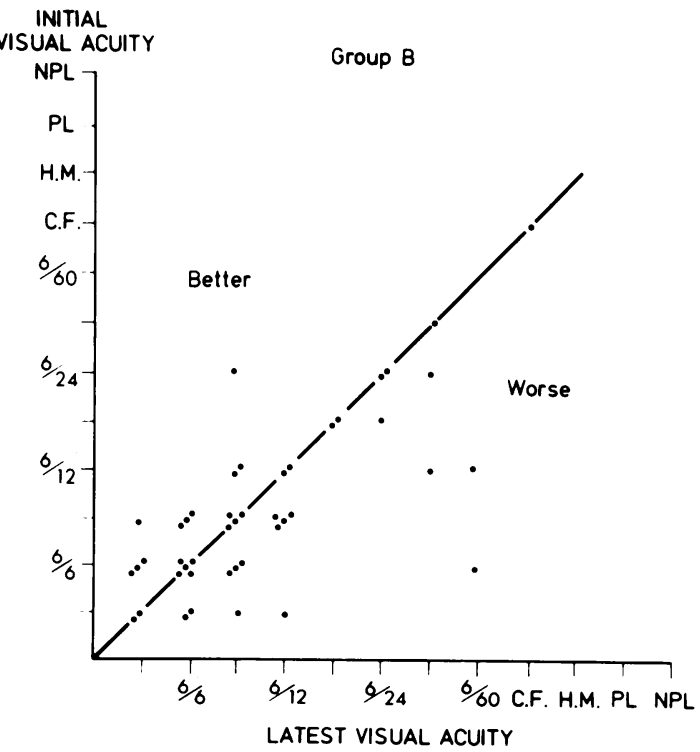

Fig. 7 Change in visual acuity from diagnosis to latest follow-up (mean=33 months) in group B. Although the data are not statistically different from those of group $A$, no group $B$ eyes lost central fixation. 
Table 10 Data for cataract at diagnosis and at final followup. The incidence is similar in the two groups, but group $A$ had had only half the number of operations and has a shorter postoperative follow-up

\begin{tabular}{|c|c|c|c|c|c|c|}
\hline \multirow[t]{2}{*}{ Group } & \multirow[t]{2}{*}{$n$} & \multirow{2}{*}{$\begin{array}{l}\text { Cataract } \\
\text { at } \\
\text { diagnosis }\end{array}$} & \multicolumn{3}{|c|}{$\begin{array}{l}\text { Progressive cataract reducing } \\
\text { vision }>1 \text { line }\end{array}$} & \multirow{2}{*}{$\begin{array}{l}\text { Mean } \\
\text { postoperative } \\
\text { follow-up }\end{array}$} \\
\hline & & & $\begin{array}{l}\text { Pre } \\
\text { existing }\end{array}$ & New & Total & \\
\hline $\mathbf{A}$ & 53 & 11 & 1 & 5 & 6 & 22 months \\
\hline B & 46 & 9 & 2 & 3 & 5 & 33 months \\
\hline
\end{tabular}

than modern medical therapy. Although delay does not compromise the pressure reducing effect of the operation, it does jeopardise preservation of visual field. Twice as many patients in Group A lose field and to a more severe degree than group $B$. The frequency of postoperative field loss with normal pressure after early surgery in this study is comparable to that noted by Kidd and O'Connor ${ }^{14}$ in their study of field loss after trabeculectomy as part of conventional management. This confirms that, even with surgery successfully reducing intraocular pressure, there is further loss of field in some cases. If this is, as it seems, a slow and at present untreatable deterioration, every chance must be taken to achieve optimum conditions as quickly as possible, and the results presented here suggest for the first time that a trial of initial medical therapy is an unacceptable risk which may allow unnecessary extra deterioration in visual field. We are unable to predict at diagnosis those patients who will show progressive visual field $\operatorname{loss}^{1516}$ and therefore cannot accurately select those for whom medical (or laser) therapy will be adequate.

The crude categories of field loss used in this study are not as elegant as more detailed mathematical analysis, but they may be defended as they divide the study population evenly across the 5 stages chosen. Of greater value is that they mark steps in a progression which are clearly significant in the progress of a glaucoma patient. Practising clinicians may therefore find this visual field analysis to be of important clinical as well as statistical significance.

Many surgeons are hesiant to operate early because they believe postoperative cataract may eventually jeopardise visual acuity, and in a very few cases there may be more dramatic surgical complications. Our results indicate no difference in visual acuity between the trial groups at present follow-up. Although numbers are small, with cataract appearing in only $10 \%$, the trend of the data suggests that group A develop cataract just as often as group B despite having only half the number of operations and shorter postoperative follow-up. This may indicate that either medical therapy is equally cataractogenic or the delayed operation carries an increased risk over early operation. More data are required to clarify this point. It is surprising that, where progressive cataract has occurred, it is usually as a new feature and not in those eyes showing early cataract before treatment.

Where less than perfect supervision is available, the poorer performance of the conventional treatment plan may be even more marked, as there may be delay in recognition of unsatisfactory intraocular pressure or deterioration of visual field. In many countries prolonged medical therapy and close supervision are impossible, and surgeons already practise early trabeculectomy. It now seems evident that this may also be the better policy even when close supervision of medically treated patients is possible. Indeed the conditions of the trial are such that it may have provided closer than normal supervision of medical treatment. The annual assessment by the trial investigator may have provided extra data or merely extra incentive for the referring surgeon to look more closely at each case. Again it must be emphasised that these results apply to the more severe cases of established glaucoma. A different strategy may be appropriate for less advanced cases. Before individual surgeons adopt the policy of early operation it is essential that their own surgical results are seen to be as safe and effective as in the published literature.

We thank the following for allocating patients to the trial: $\mathrm{Dr} T$ Barrie, D J S Cant, D J Dudgeon, Professor W S Foulds, Professor J V Forrester, Dr P M Kyle, Dr M LeMay. We are indebted to Miss Pauline Johnston for typing the manuscript and to Dr D Allan for help with statistical analysis. Dr John Clarke, Information Services Unit, Greater Glasgow Health Board, performed the life table analysis.

\section{References}

1 Jay JL. Earlier trabeculectomy. Trans Ophthalmol Soc UK 1983; 103: 35-8.

2 Migdal C, Hitchings R. Control of chronic simple glaucoma with primary medical, surgical and laser treatment. Trans Ophthalmol Soc UK 1986; 105: 653-6.

3 Norell S. Medication behaviour, a study of outpatients treated with pilocarpine eye drops for primary open angle glaucoma. Acta Ophthalmol (Kbh) 1980; suppl 143: 28.

4 Granstrom PA. Glaucoma patients not compliant with their drug therapy: clinical and behavioural aspects. Br J Ophthalmol 1982; 66: 464-70.

5 McKean JM, Elkington AR. Compliance with treatment of patients with chronic open angle glaucoma. $\mathrm{Br} J$ Ophthalmol 1983; 67: 46-9.

6 Smith RJH. Medical versus surgical therapy in glaucoma simplex. Br J Ophthalmol 1972; 56: 277-83.

7 Smith RJH. The enigma of primary open angle glaucoma. Trans Ophthalmol Soc UK 1986; 105: 618-33.

8 Murray SB, Jay JL. Trabeculectomy: its role in the management of glaucoma. Trans Ophthalmol Soc UK 1979; 99: 492-4.

9 Jay JL, Murray SB. Characteristics of reduction of intraocular pressure after trabeculectomy. Br J Ophthalmol 1980; 100: 432-5. 
10 Watson PG. Discussion of paper by Marmion VG: Anterior sclerotomy - a controlled trial. Trans Ophthalmol Soc UK 1969; 89: 523-6.

11 Watson PG. Trabeculectomy - a modified ab externo technique. Ann Ophthalmol 1970; 2: 199-205.

12 C Lopez A, C Fernandez V, Zato MA, A Rodriguez U. Medical treatment preceding surgery for glaucoma. Arch Soc Esp Oftalmol 1983; 44: 429-36.

13 Gilbert CM, Brown RH, Lynch MG. The effect of argon laser trabeculoplasty on the rate of filtering surgery. Ophthalmology 1986; 93: 362-5.
14 Kidd MN, O’Connor M. Progression of field loss after trabeculectomy: a five-year follow-up. Br J Ophthalmol 1985; 69: 82731.

15 Armaly MF. Lessons to be learned from the collaborative glaucoma survey. Surv Ophthalmol 1980; 25: 139-44.

16 Richler M, Werner EB, Thomas D. Risk factors for progression of visual field defects in medically treated patients with glaucoma. Can J Ophthalmol 1982; 17: 245-8.

Accepted for publication 3 September 1987. 